\title{
Literature Review for the Type of Interview in Qualitative Research
}

\author{
Essa Adhabi ${ }^{1, *} \&$ Christina Blash Anozie ${ }^{2}$ \\ ${ }^{1}$ Jazan University, Saudi Arabia \\ ${ }^{2}$ Social Work Faculty, MacMurray College, Illinois, United States of America \\ *Correspondence: Jazan University, Saudi Arabia. E-mail: essaadhabi1@hotmail.com
}

Received: July 10, 2017 Accepted: August 2, 2017 Published: September 20, 2017

doi:10.5296/ije.v9i3.11483 URL: https://doi.org/10.5296/ije.v9i3.11483

\begin{abstract}
In carrying out qualitative studies, the important issue is the quality of data collected, which is dependent on the mode of data collection used. The interview is one of the data collection techniques for qualitative researchers. Distinct from other methods, interviews have unique features that make them superior. As such, the current study explores relevant issues that are linked to interviews, especially aspects that make them central to qualitative data collection. Besides the historical appeal, the discussion covers the advantages a researcher experiences while using interviews to collect data. They require a personal commitment of both the participant and researcher. Significantly, time and resource allocation are also required. With the emerging technology, implementation of the interview process is becoming flexible thus moving away from the rigid face to face mode. Besides their strengths, there are also challenges and ethical dilemmas that are linked to interviews. As a perfect qualitative data collection method, researchers have professional issues that they have a deal with throughout the process. The link between all these issues is the subject area of the current discussion, which tackles each factor separately.
\end{abstract}

Keywords: Qualitative research, research designs, interview techniques. 


\section{Introduction}

Interviews form the backbone of primary data collection in qualitative research designs. Unlike quantitative studies, the scope of a qualitative study is linked to the agenda of exploring and justifying why a particular phenomenon is a way it is (Stewart, Gill, Chadwick \&Treasure, 2008). As such, effective methods of primary data collection are required, and at the center of them, is the interview method. An interview is a necessary tool in qualitative healthcare studies (Gill, Stewart, Treasure \& Chadwick, 2008). Significantly, it is evident that interviews are compatible with an experimental or a phenomenological research paradigm (Aliyu, Bello, Kasim \& Martin, 2014). Therefore, it is based on the unique position occupied by interviews with regards to the docket of qualitative studies that the current analysis analyzes it on a more detailed level. Besides providing an overview of the concept's history and definition, other aspects to be highlighted in the include types, strengths, and weaknesses, how it is carried out, ethical dilemmas linked to it, and conclude with the challenges. All these factors validate the presence of interviews at the heart of qualitative studies and why it remains such an important data collection tool.

\section{History and Development of interviews}

The use of interviews in qualitative research does not have a longer history. Qualitative interviews have their roots in the "in the anthropology and sociology of the early decades of the twentieth century" (Edwards and Holland, 2013). Despite the limited historical coverage, qualitative interviews have managed to advance and fundamentally develop significant aspects nevertheless. As explored further, it is evident that the development of the qualitative interviews is linked to the philosophical development of the research paradigms (Edwards \& Holland, 2013). The interplay between epistemological and philosophical aspects of understanding the social life has had an impact on the relationship between the researcher, the researched, and the research (Edwards \& Holland, 2013). As such, these distinct variables, which are dependent on the manifestation of research philosophies, have ended up determining the way interviews are used in qualitative research. From 1900, nine to ten phases of interview development are all linked to the disposition of research philosophies. For instance, the way positivist researchers in 1900 conceptualized qualitative interviews is not the way they were customized by the post-positivist researchers in the 1970s (Edwards \&Holland, 2013).

With each philosophical research representation, the approach from speculation towards what is exactly known changes. Significantly, the approach towards analyzing relevant aspects of social life also changes, which are important attributes that can be linked to the functional utilization of interviews as tools of qualitative research. Within the docket of positivism, despite it being a complex philosophy that cannot be comprehended easily, its principality is based on exploring the reality and the truth as it pertains a given phenomenon (Aliyu et al., 2014). As such, the positivist approach towards the interview process will be more objective rather than subjective. This is also evident because the introduction of qualitative design in the field of clinical research in the 1970 s and 80 s exposed the docket to numerous forms of 
qualitative interviews, an aspect that favorably expanded which data and how data significant to pending studies was being collected (DiCicco-Bloom \& Crabtree, 2006). In general, it is important to acknowledge that the development of qualitative interview based on existing research paradigms has effectively defined its role as a reputable qualitative data collection tool.

\section{Definition of Interview in Qualitative Research}

As complex as the concept appears to be, the interview can be simply described as a form of consultation where the researcher seeks to know more of an issue as opinionated by the individual being asked. In research, this form of consultation is motivated by a reputable purpose. As such, an interview can be comprehended as an interactive process where a person asks questions to seek particular information. From a scholarly point of view, Sewell (n.d) defines interviews in qualitative research as "attempts to understand the world from the subject's point of view, to unfold the meaning of peoples' experiences, to uncover their lived world before scientific explanations." As appreciated by other scholars, the qualitative interview is central to data collection (Gill et al., 2008). However, the most important component is that for the information obtained to be more authentic, the researcher has to create a good connection with the source. Interviewers are specialized people who act professionally to seek relevant information from subjects to validate their research hypotheses. Significantly, the subjects of the interview process are the interviewees (Edwards \& Holland, 2013).

\section{Types of Interviews}

Interviews can be categorized from their nature of implementation to their ideal motives in any qualitative study (Edwards \& Holland, 2013). Based on their nature, interviews can either be classified as formal or informal. Informal interviews are part of the daily lives people experience. The informal modes of consultations that people respond to the code of information seeking, which makes them interviews by default. While they can be used for qualitative studies, their application is limited based on the intensity of most topics under study. On the other hand, formal interviews are very rampant, more so in the professional world. Formal interviews or professional interviews as they are also termed are carried out by a lead analyst, an aspect that is no emphasized in informal interviews. The interviewer is in charge of the entire process, and his/her role is to ensure that the subject gains an understanding of the issue under analysis.

Besides the above section where interviews are categorized based on their formal nature, they are widely classified by their position in qualitative researches. As such, the three common types of interviews include; structured semi-structured and unstructured interviews (Edwards \& Holland, 2013; Stuckey, 2013; Gill et al., 2008; Jamshed, 2014; DiCicco-Bloom \& Crabtree, 2006). Besides the motive of the interview, the main difference between the types mentioned is based on the power possessed by the interviewer. In each category, the researcher assumes 
some degree of responsibility. Each of these widely conceptualized types is analyzed further to create a better understanding of why it is relevant in qualitative studies.

\section{Structured Interview}

Analysts acknowledge the fact that no qualitative interview lacks structure (Jamshed, 2014). However, the degree of rigidity in this form of interview is very different. Structured interviews are fully controlled by the interviewer (who possesses much power) and as such, gives the interviewee less room to be flexible and casual (Stuckey, 2013). Structured qualitative interviews are similar to job interviews. The natures of questions asked by the researcher are very short, and the subjects are expected to respond in a similar fashion, with short and straightforward answers. Based on the principles of a structured interview, it is evident that the interview environment is very tense and can spook unease subjects to give baseless responses. Structured interviews have a set of guidelines which must be clearly observed by the researcher (Stuckey, 2013). The researcher has to adhere to the sequence of questions and question wording during the process. In explaining the response, no participant is allowed to answer another subject's questions. Stuckey (2013) indicates that the researcher should not agree, disagree or suggest an answer. Significantly, in structured interviews, there is no interpretation of the question. The rules also cover improvising, where the research is to do no such thing. It is based on the rigid nature of structure interviews that analysts rate them unfavorably in qualitative studies (DiCicco-Bloom \& Crabtree, 2006). The two scholars indicate that structured interviews are favorable for quantitative data.

\section{Semi-Structured Interviews}

As analysts point out, this is the most used type of interview in qualitative researchers (Alshenqeeti, 2014). Just like structured interviews, this type of interview also an outline of topics and questions prepared by the researcher (Stuckey, 2013). However, unlike the structured, semi-structured interviews have no rigid adherence. Their implementation is dependent on how the interviewee responds to the question or topics laid across by the researcher. By borrowing a leaf from the field of qualitative diabetes research, scholars assert that the researcher is mandated to provide the subject with some topics reflecting the issue under study, whereby one is to explore the topic that the interviewee is comfortable with (Stuckey, 2013). Although there is a set of guiding question, the response of the subject gives the researcher the flexibility to pose more enhanced questions than the initially drafted ones. This notion is also upheld by other scholars who assert that semi-structured in-depth interviews are the sole source of information for qualitative researchers (DiCicco-Bloom \& Crabtree, 2006).

Based on their flexibility, interviews can either be individual or did in groups. The advantage of dealing with an individual conforms to the title 'in-depth interview', whereby the researcher can go deeper and highlight on personal issues. For biography related researchers, semi-structure interviews are ideal for the task (DiCicco-Bloom \& Crabtree, 2006). Similarly, 
semi-structured interviews for groups are also perfect as they accord the researcher enough time to explore on a subject issues. In addition to this, the selection of interviewees should be a homogenous process whereby the selected participants are related to the study question (DiCicco-Bloom \& Crabtree, 2006). As such, it is significant to acknowledge semi-structured interviews as the ideal data collection mechanism for qualitative studies.

\section{Unstructured Interviews}

Based on the current understanding, no interview can be qualified as truly unstructured. However, certain interviews are disjointed in their nature of implementation that they qualify the tag name. This form of interview has its roots in the ethnographic tradition of anthropology (DiCicco-Bloom \& Crabtree, 2006). In studying certain aspects of pressing social issues, researchers have to become part of what they are studying. Doing so enables them to observe, point out the lead subjects and informally ask them questions while they take notes. This form of interviews needs to be conceptualized as the narrative interview (Stuckey, 2013). Although through different conceptualization, point out that the narrative mode of question is a type of unstructured interview (Muylaert, Sarubbi Jr., Gallo, Neto, \& Reis, 2014). Significantly, unstructured interviews are controlled conversations that bend towards the interests of the researcher. As explored further, there are different subtypes of the unstructured interviews (Jamshed, 2014). One of them is the non-directive interview, where the researcher has no pre-planned questions. Significantly, there is the focused interview where the researcher knows the subject and manipulates him/her towards a relevant topic of interest. Informal interviews cover the better part of unstructured interviews. It is, therefore, significant to acknowledge that regards of their irregular structure, unstructured interviews are still a significant qualitative data collection tool.

\section{Focus Groups}

Focus groups are mainly data collection methods which use semi-structured group interviews to collect the data. These groups are usually supervised by a group leader. The methods of data collection in focus groups may vary in design (Creswell, 2013). Various groups may be formed depending on the standardization of questions, number of focus groups conducted, and number of participants per group and the level of moderation involved among many other aspects (Ladimeji, 2013).

\section{Types of Interview Techniques}

Different from the general types of interviews explored above, interview techniques represent the unique mechanisms through which interviews can be accomplished. These interview techniques can reflect any the research interviews discussed above. Face to face and telephone interview to be the most utilized techniques (Jackle, Roberts, \& Lynn, 2006). Besides the two mentioned techniques, messenger and e-mail interviews are also part of the 
interview techniques (Opdenakker, 2006). Traditionally, face to face interview was and continue to be the most preferred mode of interview. However, with the development of technology, techniques of the interview have been advancing with time. From the telephone interview, the researcher can use emails and messengers to accomplish the same purpose. Significant to this is the recent development of the social media. Scholars analyze the authenticity of Skype interviews in collecting qualitative data. In their right, Skype and other audio-visual technological platforms are by default, an extension of the face to face interview (Sullivan, 2013). It is the presence of numerous techniques of carrying out qualitative interviews that make an appropriate data collection tool.

\section{Advantages and Disadvantages of Interviews}

Just like any qualitative data collection mechanism, interviews exhibit their superiority and weakness. However, their comprehensive use in qualitative studies is because the strengths outweigh the weaknesses.

\subsection{Advantages}

From a general perspective, interviews have numerous advantages that conform to the nature of a qualitative research paradigm. One of the pertinent aspects emphasized on by Sewell is that interviews provide the participants with the much-needed flexibility of explaining issues based on how well they know them. To the qualitative researcher, this is significant as the central issue in qualitative research is to justify the occurrence of a particular phenomenon. Significantly, Interviews, mainly semi-structured and unstructured allow the researcher to interject where necessary and ensure that the subject understands the topic or question under scrutiny. In addition to this, interviewers get to use their interpersonal skills to explore on significant issues raised by the participant, aspects that are central to comprehensive data collection. However, the general analytical approach preferred by Sewell, this discussion also glances at the specific approach preferred by Opdenakker (2006). The scholar deduces the strengths of qualitative interview based on the techniques used, which include face to face, telephone, messenger and e-mail interviews.

Face to face interview is advantageous based on the amount of data that can be collected (Opdenakker, 2006). In general interview, time is a major factor, which well accounted for when the face to face mode is applied. The researcher has the time to get comfortable and articulate issues vividly with the subject. Besides the aspect of quantity, the quality of data collected is also high. With the possibility of sticking to visual aids, the subject is much likely to understand the question and yield appropriate responses, compared to telephone or mail interviews. Face to face interviews is also perfect for groups (Doyle, 2005). The advantages of telephone interview include a wide geographical coverage, easy to contact inaccessible individuals, superior for contacting people in closed sites or war tone areas, and relevant in dealing with sensitive issues where personal contact is not required (Opdenakker, 2006). Messenger chats and e-mail alike save on time and cost of interviews. 


\subsection{Disadvantages}

The disadvantages of qualitative interviews are also linked to each technique used. The downsides of face to face interviews include being costly and requiring a long time to complete (Doyle, 2005). In face to face interaction, the research needs to travel or pay for the participants' fare to the interview sites. Significantly, interviewees also need to be trained, all aspects that amount to costliness and much time was taken. Consequently, face to face interviews are physically limited to a single geographical region while they put the interviewee on the spot as they require immediate responses. Analysts also indicate that is easy to introduce interviewer bias (Doyle, 2005). The downsides of telephone interview include short interviews due to limed resources, and like other technological platforms, mainly mail and messenger, physical aids cannot be used for further justification (Opdenakker,2006). Significantly, it is hard for the researcher to identify the physical or emotional state of the participant.

\section{The Interview Process}

The semi-structured in-depth interview is most preferred for qualitative data collection (DiCicco-Bloom \& Crabtree, 2006). As such, the description of the interview process in the section is fundamentally linked to the tenets of a semi-structured interview.

For a proper interview to be conducted, the researcher should begin by appropriately assembling the participants (DiCicco-Bloom \& Crabtree, 2006). Based on the nature of the study, this can be accomplished either in groups or individually. Besides the unbiased selection, the participants need to be prepared, mainly through light training by the researcher (Doyle, 2005); Hancock, Windridge, and Ockleford, 2009). After a consideration of the pertinent selection factors, analysts pinpoint a list of other simple but significant aspects that have to be considered for an interview process (Jacob \& Furgerson, 2012). One aspect is that the researcher needs to pick a topic that is interesting to him/her, which will perfectly guide the research question. Consequently, the researcher also needs to rely on open-ended questions to elucidate the appropriate response of the participant.

Significantly, the researcher needs to start with basics. There are main aspects that include appropriate personal and topic introduction, coupled with the construction of a good rapport to underline the efficiency of the entire process. This means that researcher will begin by easy questions moving towards the complex ones. With all important factors under consideration, the interview should not be long. The interviewer should assert some authority, but not so much that it makes the participant tense (DiCicco-Bloom \& Crabtree, 2006). During the process, the collected data can be stored in some ways. One way is through note taking. Besides being a simple and easy tool to use, note-taking does not elucidate unwanted reactions from the participant. Significantly, other modes of storing interview data include audiotape recording and videotape recording. For these two forms to be used, the consent of the participant is required (Harell \& Bradley, 2009). Besides the issue of consent, they are appropriate for information storage. Backgrounds free of noise and high-quality tapes are 
fundamental to high quality of data retrieved from storage. Although not very conclusive, this analysis has presented the essential aspects that underlie a concise process of the semi-structured interview.

\section{Purpose for Qualitative Interviews}

"The purpose of the research interview is to explore the views, experiences, beliefs, and motivations of individuals on specific matters" (Gill et al. (2008). For instance, in the field of dental care, one issue that can be explored is to understand what motivates dentists to use evidence-based practice. Significantly, another reason for interviews is that as conceptualized by an earlier anthropologist, the participant's point of view elucidates a stronger meaning (Legard, Keegan, \& Ward, 2003). From an analytical point of view, interviews are used to collect the same data that can be collected by other qualitative or quantitative data collection mechanisms. However, the difference as vividly pointed out is based on the efficiency of interviews. Based on their unique structures, the interviewers can go deep into exploiting a particular phenomenon, more than any other data collection mechanism. Significantly, scholars also point out some factors that are linked to the ability of qualitative interviews in digging deeper and fostering the understanding of pertinent social issues (Edwards \& Holland, 2013). In addition to this, qualitative interviews are fundamentally accredited for developing statistics and scientific procedures. It is, therefore, based on such strengths that interviews remain at the center of qualitative studies.

\section{Ethical Concerns of Interviews}

The sole purpose of ethics in scientific studies is to govern the predicament of both the participant and the researcher. In a typical qualitative study, analysts point out that the interaction between the participant and the researcher during data collection can foster moral consequences. As such, there is a need to put in place distinct guidelines to be followed in avoidance of ethical repercussions. Collectively, some of the issues that raise ethical concerns in qualitative studies include confidentiality and informed consent (Corti, Day \& Backhouse, 2000; Orb, Eisenhauer \& Wynaden, 2001). Other aspects also considered include anonymity, and potential impact and potential harm to the participant (Halai, 2006; Stevens, 2013; Sanjari, Bahramnezhad, Fomani, Shoghi \& Cheraghi, 2014). While these concerns may be reflected to be affecting qualitative studies in general, experts point out that they are very relevant to the disposition of qualitative interviews. However, narrowing down to qualitative interviews, research scholars say that the four ethical issues affecting the credibility of interviews include: "Reducing the risk of unanticipated harm, protecting the interviewee's information, effectively informing the interviewees about the nature of the study, and reducing the risk of exploitation" (DiCicco-Bloom \& Crabtree, 2006)

Tackling each of issue separately, analysts pinpoint the actual differences and why each aspect matters. For instance, privacy is often treated as confidentiality, while in reality, they are two distinct aspects that need to be respected separately (Allmark et al., 2009). Privacy 
manifests when the researcher indulges the subject on sensitive issues that one is uncomfortable with. On the other hand, confidentiality is breached when the researcher publicizes private issues that were discussed. Significantly, the aspect of informed consent where researchers expect participants to open up fully on partial information (Allmark et al., 2009). To avoid such a scenario, there is the need of researches adapting to the continuous model of informed consent, where the participant is reassured throughout the study when sensitive issues are tackled.

Other ethical themes highlighted by analysts also include the dual involvement of the researcher and prevention of emotional harm (Allmark et al., 2009). Dual involvement explores on the other roles that a researcher must embrace to build a good rapport with the subject. For instance, friendship is one of the good examples. However, friendship is not expected to derail the purpose of the interview. Immoral instances would be where the researcher sleeps with his/her participant, thus jeopardizing the interview process. Collectively, these are the most pressing moral dilemmas that cloud the interview process, and to avoid them; a researcher needs to be guided by the professional code of standards.

\section{Challenges of Interviews}

Criticism on interviews emanates where their accomplishment is impaired. The lack of objective clarity for qualitative interviews is justified by the challenges that arise during its implementation (Edwards \& Holland, 2013). There are also some obstacles that undermine the perfect implementation of qualitative interviews. One of the significant issues that researchers face is deciding who they want to talk to, which is distinct from the problem of participant selection (Partington, 2001; Witchsey, Murphy-Hill, \& Xiao, 2013). The question of 'who' identifies the nature of population that the research wants to talk to. Is it men, children, or a specific ethnic group? Determining the 'who' part of the interview factors in the aspect of communication (Roulston, 2011). For instance, when dealing with patients exhibiting dementia of the Alzheimer, medical scholars point out the importance of good communication skills that favors the response of such individuals (Beuscher \& Grando, 2009). As such, based on the type of people interviewed, proper communication as immediate challenge remains a reality. Consequently, researchers all face the dilemma of participant selection. With many potential subjects available, the researcher has to utilize his/her option well for quality results, an aspect that remains very challenging.

Other pertinent factors that jeopardize the process of qualitative interviews as analyzed include adapting to the optimal interview structure and preparing early enough (Witchsey et al., 2013). For instance, if it is the semi-structured interview, the researcher has to show consistency throughout, an aspect that can be challenging. Significantly, most researchers do not get enough time to prepare for their interviews, an aspect that derails their ability in knowing what may be interesting or not interesting to ask the participants (Drew, 2014). Amongst other challenges, these are some of the major ones that researchers need to work on avoiding them. 


\section{Conclusion}

Interviews remain central to the authenticity of the data collected for qualitative studies. According to the covered context, although they have a limited historical timeline, interviews have developed alongside the philosophical reflection of the existing research paradigms to remains a perfect tool in qualitative, and even quantitative studies. Significantly, of the three types of qualitative interviews, the semi-structured approach has been validated to be ideal for qualitative data collection. This is because it gives the researcher the flexibility of twisting certain variables to develop a good connection with the participant. Despite the numerous challenges and downsides that are linked to qualitative interviews, their ability to engage the participants for a deeper understanding of the phenomenon under study makes them superior. For qualitative interviews to remain morally upright, researchers need to exhibit professional maturity. Similar to other modes of data collection, significant resources need to be allocated into qualitative interviews to ensure their perfect implementation. As such, the continued application of interviews strengthens the field of qualitative study by providing high quality and expansive data.

\section{References}

Aliyu, A. A., Bello, M. U., Kasim, R., \& Martin, D. (2014). Positivist and Non-Positivist Paradigm in Social Science Research: Conflicting Paradigms or Perfect Partners?. Journal of Management and Sustainability, 4(3), 79-95. https://doi.org/10.5539/jms.v4n3p79

Allmark, P., Boote, J., Chambers, E., Clarke, A., McDonnell, A., Thompson, A., \& Tod, A. M. (2009). Ethical issues in the use of in-depth interviews: literature review and discussion. Research ethics review, 5(2), 48-54. https://doi.org/10.1177/174701610900500203

Alshenqeeti, H. (2014). Interviewing as a Data Collection Method: A Critical Review. English Linguistics Research, 3(1), 39. https://doi.org/10.5430/elr.v3n1p39

Beuscher, L., \& Grando, V. T. (2009). Challenges in conducting qualitative research with individuals with dementia. Research in Gerontological Nursing, 2(1), 6-11. https://doi.org/10.3928/19404921-20090101-04

Corti, L., Day, A., \& Backhouse, G. (2000, December). Confidentiality and informed consent: Issues for consideration in the preservation of and provision of access to qualitative data archives. In Forum Qualitative Sozialforschung/Forum: Qualitative Social Research $1(3)$.

Creswell, J. W. (2012). Qualitative inquiry and research design: Choosing among five approaches. Sage publications.

DiCicco-Bloom, B., \& Crabtree, B. F. (2006). The qualitative research interview. Medical Education, 40(4), 314-321.

Drew, H. (2014). Overcoming barriers: Qualitative interviews with German elites. Electronic 
Journal of Business Research Methods, 12(2), 77-86.

Edwards, R., \& Holland, J. (2013). What is qualitative interviewing?. A\&C Black. Retrieved from http://eprints.ncrm.ac.uk/3276/1/complete_proofs.pdf

Gill, P., Stewart, K., Treasure, E., \& Chadwick, B. (2008). Methods of data collection in qualitative research: interviews and focus groups. British dental journal, 204(6), 291-295. https://doi.org/10.1038/bdj.2008.192

Halai, A. (2006). Ethics in qualitative research: Issues and challenges. EdQual A Research Programme Consortium on Implementing Education Quality in Low-Income Countries, 4 , 2-12.

Hancock, B., Ockleford, E., \& Windridge, K. (2009). An introduction to qualitative research. Nottingham: Trent focus group.

Harrell, M. C., \& Bradley, M. A. (2009). Data collection methods. Semi-structured interviews and focus groups. RAND National Defense Research Inst Santa Monica CA.

Jackle, A., Roberts, C., \& Lynn, P. (2006). Telephone versus face-to-face interviewing: mode effects on data quality and likely causes: report on phase II of the ESS-Gallup mixed mode methodology project. Institute for Social and Economic Research.

Jacob, S. A., \& Furgerson, S. P. (2012). Writing interview protocols and conducting interviews: Tips for students new to the field of qualitative research. The Qualitative Report, 17(42), $1-10$.

Jamshed, S. (2014). Qualitative research method-interviewing and observation. Journal of basic and clinical pharmacy, 5(4), 87-88. https://doi.org/10.4103/0976-0105.141942

Legard, R., Keegan, J., \& Ward, K. (2003). In-depth interviews. Qualitative research practice: A guide for social science students and researchers, 138-169.

Ladimeji, K. (2013, April 03). Four types of interviewer bias - and how to eliminate them. Retrieved

from https://www.recruiter.com/i/4-types-of-interviewer-bias-and-how-to-eliminate-them/

Muylaert, C. J., Sarubbi Jr, V., Gallo, P. R., Neto, M. L. R., \& Reis, A. O. A. (2014). Narrative interviews: an important resource in qualitative research. Revista da Escola de $\begin{array}{llll}\text { Enfermagem } \quad d a & \text { USP, } & \text { 48(SPE2), } & \text { 184-189. }\end{array}$ https://doi.org/10.1590/S0080-623420140000800027

Opdenakker, R. (2006, September). Advantages and disadvantages of four interview techniques in qualitative research. In Forum Qualitative Sozialforschung/Forum: Qualitative Social Research, 7(4).

Orb, A., Eisenhauer, L., \& Wynaden, D. (2001). Ethics in qualitative research. Journal of nursing scholarship, 33(1), 93-96. https://doi.org/10.1111/j.1547-5069.2001.00093.x

Partington, G. (2001). Qualitative research interviews: Identifying problems in technique. 
Retrieved from http://ro.ecu.edu.au/cgi/viewcontent.cgi?article=5367\&context=ecuworks

Roulston, K. (2011). Working through challenges in doing interview research. International Journal of Qualitative Methods, 10(4), 348-366. https://doi.org/10.1177/160940691101000404

Sanjari, M., Bahramnezhad, F., Fomani, F. K., Shoghi, M., \& Cheraghi, M. A. (2014). Ethical challenges of researchers in qualitative studies: the necessity to develop a specific guideline. Journal of medical ethics and history of medicine, 7(14).

Sewell, M. (n.d). The use of qualitative interviews in evaluation. The University of Arizona. https://cals.arizona.edu/sfcs/cyfernet/cyfar/Intervu5.htms

Stevens, M. (2013). Ethical issues in qualitative research. King's College London. Retrieved from

http://www.kcl.ac.uk/sspp/policyinstitute/scwru/pubs/2013/conf/stevens14feb13.pdf

Stewart, K., Gill, P., Chadwick, B., \& Treasure, E. (2008). Qualitative research in dentistry. British dental journal, 204(5), 235-239. https://doi.org/10.1038/bdj.2008.149

Stuckey, H. L. (2013). Three types of interviews: Qualitative research methods in social health. Journal of Social Health and Diabetes, 1(2), 56-59. https://doi.org/10.4103/2321-0656.115294

Sullivan, J. R. (2013). Skype: An appropriate method of data collection for qualitative interviews?. The Hilltop Review, 6(1), 54-60.

Witschey, J., Murphy-Hill, E., \& Xiao, S. (2013, May). Conducting interview studies: Challenges, lessons learned, and open questions. In Conducting Empirical Studies in Industry (CESI), 2013 1st International Workshop on IEEE (pp. 51-54).

\section{Copyright Disclaimer}

Copyright for this article is retained by the author(s), with first publication rights granted to the journal.

This is an open-access article distributed under the terms and conditions of the Creative Commons Attribution license (http://creativecommons.org/licenses/by/3.0/). 